\title{
Distinct organic carbon dynamics in the Irrawaddy, Salween, and Mekong river basins
}

\section{J. JOTAUTAS BARONAS ${ }^{1,2}$, ROBERT G HILTON ${ }^{3}$, EMILY ISABEL STEVENSON ${ }^{1}$, MIKE BICKLE ${ }^{1}$ AND EDWARD TIPPER $^{4}$}

${ }^{1}$ University of Cambridge

${ }^{2}$ Institut de Physique du Globe de Paris

${ }^{3}$ Durham University

${ }^{4}$ Cambridge

Presenting Author: jotautas.baronas@gmail.com

The continental organic carbon cycle plays an important role in controlling atmospheric $\mathrm{CO}_{2}$ and $\mathrm{O}_{2}$ concentrations, and thus Earth's climate and habitability. The flux and composition of organic carbon (OC) carried by world's major rivers yields insights on the sources, storage, and cycling of OC over large, globally-relevant spatial scales.

Here, we present the measurements of particulate and dissolved OC from the Irrawaddy, Salween, and Mekong river basins in Southeast Asia. Based on ${ }^{14} \mathrm{C}$ measurements, the Irrawaddy and the Salween export a significantly aged pool of POC, with fraction modern (Fm) ranging from 0.15 to 0.89 and strongly hydrodynamically sorted with depth in the river channels. In contrast, DOC in the Irrawaddy was significantly younger $(\mathrm{Fm}=0.70-0.99)$, while in the Salween it was older $(\mathrm{Fm}$ $=0.61-0.66)$, compared to POC. The Mekong dominantly exports fine sediments rich in recent biospheric POC $(\mathrm{Fm}=0.87$ 0.97). The results indicate distinct $\mathrm{OC}$ sources and turnover dynamics in the three river basins, controlled by different geomorphic, lithologic, and anthropogenic characteristics. We estimate the combined biospheric POC flux of the three basins to be around $2.7 \mathrm{Pg} \mathrm{C} \mathrm{/} \mathrm{y,} \mathrm{similar} \mathrm{to} \mathrm{that} \mathrm{of} \mathrm{the} \mathrm{Ganges-}$ Brahmaputra system, and a petrogenic POC flux that is $10-20 \mathrm{x}$ lower than the biospheric flux.

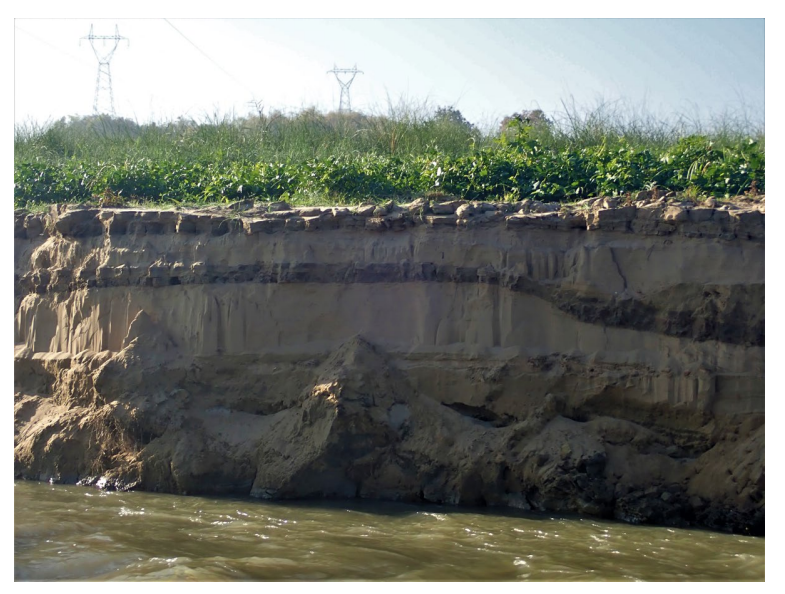

